\title{
Effectiveness of different ways of presenting neuroanatomy illustration in powerpoint slides on nursing student's short -term learning memory
}

\author{
Gyem Dorji ${ }^{1}$, Kanokwan Wetasin ${ }^{2}$, Kuenzang Chhezom ${ }^{3}$, Nargis Sultana ${ }^{4}$, Minjur Dorji ${ }^{5}$ \\ ${ }^{1,3}$ Faculty of Postgraduate Medicine, Khesar Gyalpo University of Medical Sciences of Bhutan, Thimphu, Bhutan \\ ${ }^{2}$ Boromarajonani College of Nursing Nopparat Vajira, Faculty of Nursing, PBRI, Thailand \\ ${ }^{4}$ Department of Anatomy, Bangladesh Medical College, Dhaka \\ ${ }^{5}$ Department of Medicine, Jigme Dorji Wangchuck National Referral Hospital,Thimphu, Bhutan
}

\begin{abstract}
Introduction: Neuroanatomy is considered as difficult subject as it consists mostly of complicated microscopic structures. However, understanding of the subject structure is very important for nursing students to know its functions and dysfunctions for enhancing nursing practices. To date, teaching neuroanatomy relies heavily on illustrations and the most common way is by using PowerPoint slides, but teachers are often faced with dilemma on how to use illustrations effectively. Therefore, this study was conducted to assess the effectiveness of different ways of presenting neuroanatomy illustrations in PowerPoint slides on nursing students' shortterm learning memory. Methods: The quasi-experimental study was conducted at Faculty of Nursing and Public Health, Khesar Gyalpo University of Medical Sciences of Bhutan between June 2020 and November 2020 by comparing an Experimental $(n=$ 70) and a Control group ( $n=69)$ of first year nursing students for their ability to answer questions based on those seven-way slides. Independent sample t-test was used for statistical analysis. Results: Significant difference was found at $95 \%$ CI between the performance of the Experimental and Control groups regarding Way 1 (Sequencing of labels) and Way 6 (Magnifying from the original structure) of presentation (tWay $1(135.99)=2.695, p=.008, \mathrm{~d}=.458,95 \% \mathrm{CI}=[0.059, .385]$; tWay $6(135.61)=2.351$, $p=.020, \mathrm{~d}=.399,95 \% \mathrm{CI}=.031, .355]$, respectively). Conclusions: The use of different ways like sequencing the labels and magnifying from the original structure of presenting illustration in PowerPoint slides are found to be helpful in increasing shortterm memory in students.
\end{abstract}

Keywords: Illustrations; Neuroanatomy; Powerpoint; Short-term learning memory.

\section{INTRODUCTION}

Neuroanatomy is considered as one of the most difficult and complex systems of the human body ${ }^{1}$ and use of different forms of illustration is essential for its effective teaching ${ }^{2}$. This notion of effective teaching is made possible with the aid of PowerPoint which has become the most popular multimedia software used by teachers in the classrooms worldwide ${ }^{3,4}$ even in Bhutan. However, the popularity and necessity of different styles of presenting illustration in PowerPoint among the students and teachers has not yet been examined in Khesar Gyalpo University of Medical Sciences of Bhutan (KGUMSB), the only public higher education institution that offers medical sciences including nursing education in the country.

Obviously, understanding neuroanatomy is essential for nursing students to develop their cognitive skill serving as a foundation for eliciting critical thinking which eventually help

\section{Corresponding author:}

Gyem Dorji

gyemanatomy@kgumsb.edu.bt initiating effective nursing care for the patients ${ }^{5}$. Short-term learning memory- an attentive processing that can retain limited amount of information for a short period of time- plays a major role in transferring knowledge to the long-term learning memories ${ }^{6}$. Given the complexity of neuroanatomy and the nature of novice learners who usually have no prior knowledge, the challenge lies in 'how' the teachers will design effective style of presenting to convey such complicated subject within the short-time frame to not only trigger sensory memory, but also enhance the student's short-term learning memory as well.

In view of the above rationale, the present study was designed to identify different 'ways' of presenting illustrations in PowerPoint slides, create representative slides for those ways, and then to investigate the effectiveness of those 'ways' in understanding neuroanatomy by analyzing short-term learning performances of nursing students related to the ways of presenting the illustrations.

\section{METHODS}

This quasi-experimental study was conducted from $1^{\text {st }}$ June to $30^{\text {th }}$ November 2020 at Faculty of Nursing and Public Health, 
Thimphu using Neuroanatomy illustration to $1^{\text {st }}$ year nursing students through lectures using PowerPoint slides with approval from Research Ethics Board of Health vide approval letter number REBH/ PO /2017/ 091.

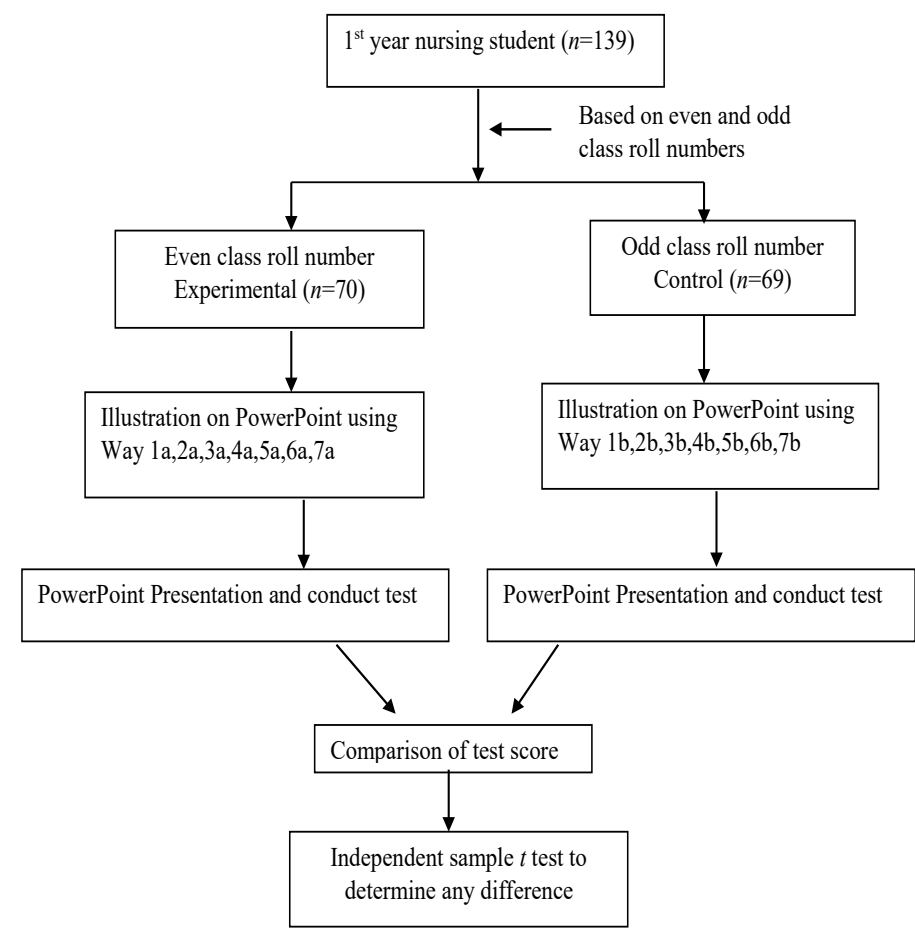

Figure 1. Flow chart of the study

A purposive sampling was performed to include an entire 2020 batch (139) of newly admitted nursing students after getting written informed consent. Since the research was on use of different illustrations in PowerPoint presentation, any student having color blindness might affect the result. To address this issue, every student's medical certificate that was submitted during the time of admission into the course was checked. It was found that there was no student having any issue of colorblindness.

The class was divided into two groups according to their class roll numbers. Students bearing even class roll numbers were assigned into Experimental group, and those with odd class roll numbers were assigned into Control group. Therefore, there were 70 students in Experimental group and 69 students in Control group. Both Experimental and Control groups had similar gender ratio as shown in Figure 2.

To evaluate the effectiveness of different ways of neuroanatomy illustration on PowerPoint slides, seven questions were prepared for the tests which measure the knowledge level of the students after the lecture for both the groups. The test included 'true or false' and 'fill in the blanks' questions. The scores for each correct answer was 1 , and the total score ranged between 0 and 7.

To ensure the content validity and language validity of the questions, an expert opinions of five expert medical educators
Two different sets of PowerPoint were prepared using the different 'way' on an illustration. Way 1a,2a,3a,4a,5a,6a, and 7a were for experimental group and way $1 b, 2 b, 3 b, 4 b, 5 b, 6 b$, and $7 \mathrm{~b}$ for the control group. The different ways was adopted from previous study ${ }^{7}$ as follows.

\section{Way 1: Sequencing of labels}

a) If labels of an illustration appear one by one

b) If labels appear at once

Way 2: Coloring of labels

a) If corresponding coloured labels are used to present different coloured parts of an illustration

b) If no coloured labels are used for different coloured parts of an illustration.

Way 3: Organizing of labels

a) If an illustration is labelled from one side

b) If an illustration is labelled from both sides.

\section{Way 4: Differentiating structure by color}

a) If an illustration is used to present different parts of an anatomical structure in different colours

b) If an illustration is presented in the natural colour of the structure.

Way 5: Converging illustration and accompanying text

a) If an illustration is directed towards an accompanying text b) If an illustration is directed away from the accompanying text.

Way 6: Magnifying from the original structure

a)If an 'inset' (an enlarged view of a particular part of a structure) is used along with the normal view of the structure

b) If an illustration is used only in its enlarged view.

Way 7: Illustrating the dynamic flow

a) If a labeled illustration is used to present a neural pathways

b) If a textual flowchart is used to present neural pathway.

were obtained. Experts analyzed the relevance of the items to the content domain and clarity, and they scored from 1 (non-relevant) to 4 (very relevant). A content validity index (CVI) was then calculated for each item and for the total set of the items. CVI for each item and the total set of the items were calculated to be 0.93 and 0.94 , respectively.

To evaluate the understandability of the knowledge questions, a pilot study was applied to 12 students who took the same course a year before. The Cronbach's alpha coefficient of the knowledge question was 0.715 .

Analyses were conducted using SPSS version 26.0 (IBM Corp, Armonk, NY). Mean, standard deviation and mean difference were used as descriptive statistics. Discrete variables were shown in numbers (n) and percentages (\%). The independent sample t test was used to examine any difference between the two groups regarding the seven different ways.

The collected answer sheets of each group was marked. Each correct response was given a score of ' 1 '. Each incorrect response and each 'undecided' response was awarded a ' 0 '. 
There was no negative scoring. SPSS version 26 was used to calculate frequency distribution, ranges, means and standard deviation as applicable. An independent sample t test was used to determine any difference between the two groups regarding any of the seven 'ways' between Experimental and Control groups. The assumption for using the $t$ test was confirmed using normality test. Levene's test for equality of variances was used to select the t-value. Effect size of each way of presentation on nursing student's short-term learning memory was calculated using Cohen's d formula (Cohen, 1992).

\section{RESULTS}

One hundred and thirty nine first year nursing students from Faculty of Nursing and Public Health were divided into two

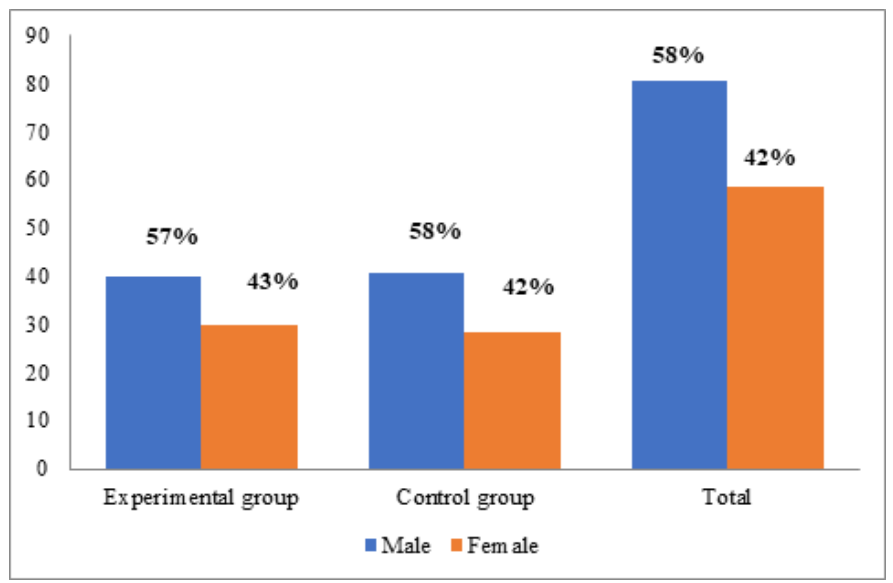

Figure 2. Percentage of gender distribution of the $1^{\text {st }}$ year nursing students who participated in the study groups, an 'Experimental' group comprising of 70 participants and a 'Control' group comprising of 69 participants. Out of 139 students, $59(42 \%)$ were female and $80(58 \%)$ were male [Figure 2].

Table 1 and Figure 3 shows the learning performances of the nursing students of Experimental group in terms of their scores were compared with corresponding Control group respectively. The Out of seven ways, way 1(Sequencing of labels) showed that 'use of the labels of an illustration appearing one by one' was significantly higher effective on nursing students' shortterm learning $($ Mean $=.69, \mathrm{SD}=.468)$ than 'use of the labels of an illustration appearing at once' (Mean $=.46, \mathrm{SD}=.502)$, tWay $1(135.99)=2.695, p=.008, \mathrm{~d}=.457,95 \% \mathrm{CI}=[0.059, .385] . \mathrm{In}$ addition, way 6 (Magnifying from the original structure) showed that 'use of an 'inset' - an enlarged view of a particular part of a structure, along with the normal view of the structure' was significantly higher effective on the students' short-term learning (Mean $=.70, \mathrm{SD}=.462)$ than 'use of an illustration only in its enlarged view’ $($ Mean $=.51, \mathrm{SD}=.504)$, tWay $6(135.61)=2.351$, $p=.020, \mathrm{~d}=.399,95 \% \mathrm{CI}=.031, .355]$.

According to Cohen (1992), an effect size of 0.20 is small; 0.50 is medium; 0.80 is large. Thus, it should be noted that an effect size for each 'way 1' and 'way 6' was small $(\mathrm{d}=$ .458 and .399 , respectively). However, combining these two significant ways would yield a stronger effect on nursing student's short-term learning memory. In addition, Figure 3 illustrates that for 'way 1' and 'way 6', its $95 \%$ Confident Interval of the mean difference between the two groups was not covered zero line of null hypotheses.

Table 1. Comparison of scores between the two groups of nursing students on seven selected ways of presenting Neuroanatomy illustrations in PowerPoint slides

\begin{tabular}{|c|c|c|c|c|c|c|}
\hline \multirow[t]{2}{*}{ Ways of presenting } & \multicolumn{2}{|l|}{ Mean ( \pm SD) score } & \multirow[t]{2}{*}{$\mathbf{t}^{*}$} & \multirow[t]{2}{*}{ Df } & \multirow[t]{2}{*}{$p$-value } & \multirow[t]{2}{*}{ Cohen's d } \\
\hline & $\begin{array}{l}\text { Experimental group } \\
(n=70)\end{array}$ & $\begin{array}{l}\text { Control group } \\
(n=69)\end{array}$ & & & & \\
\hline Way 1: Sequencing of labels & $.69( \pm .468)$ & $.46( \pm .502)$ & 2.695 & 135.993 & $0.008(\mathrm{~S})^{\dagger}$ & .458 \\
\hline Way 2: Coloring of labels & $.76( \pm .432)$ & $.71( \pm .457)$ & .623 & 137 & 0.534 & .106 \\
\hline Way 3: Organizing of labels & $.63( \pm .487)$ & $.49( \pm .505)$ & 1.616 & 136.676 & 0.108 & .274 \\
\hline $\begin{array}{l}\text { Way 4: Differentiating structure } \\
\text { by color }\end{array}$ & $.74( \pm .440)$ & $.72( \pm .450)$ & .241 & 137 & 0.810 & .040 \\
\hline $\begin{array}{l}\text { Way 5: Converging illustration and } \\
\text { accompanying text }\end{array}$ & $.66( \pm .478)$ & $.65( \pm .480)$ & .061 & 137 & 0.951 & .010 \\
\hline $\begin{array}{l}\text { Way 6: Magnifying from the } \\
\text { original structure }\end{array}$ & $.70( \pm .462)$ & $.51( \pm .504)$ & 2.351 & 135.606 & $0.020(\mathrm{~S})^{\dagger}$ & .399 \\
\hline Way 7: Illustrating the dynamic flow & $.71( \pm .455)$ & $.62( \pm .488)$ & 1.138 & 136.026 & 0.257 & .193 \\
\hline
\end{tabular}




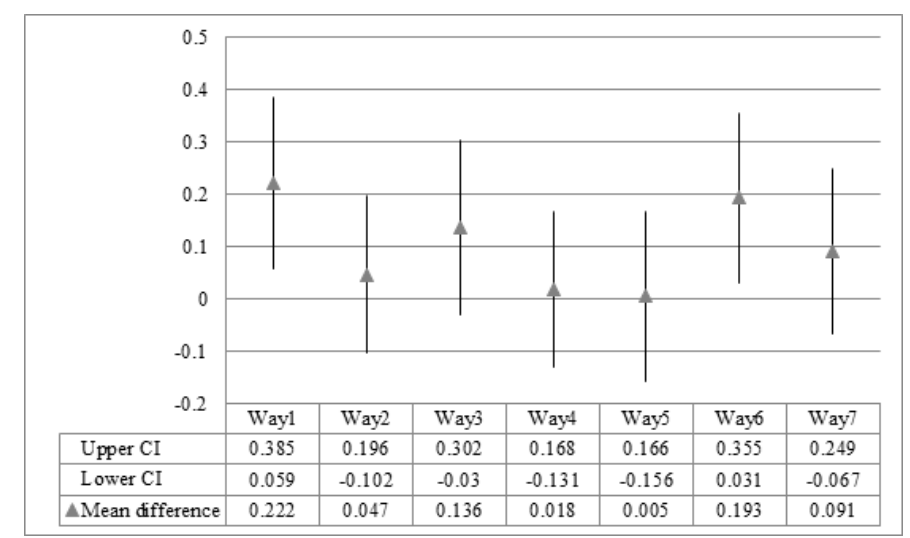

Figure $3.95 \%$ Confidence Interval of the mean difference between the two groups

\section{DISCUSSION}

The learning performance of the two groups of nursing students showed that 'sequencing of labels' by using an illustration having labels appearing one by one was more effective compared to that having labels appearing at once. It must be noted that gradual revelation of graphical material is a well-known tactic in presenting complex figures ${ }^{8}$. However, reading style varies from person to person'. Actually the effect may depend on individual learners as well ${ }^{10}$. Some may like to see things one by one. Others may like to have a broader look at all together to identify a relationship among them in order to understand or memorise them ${ }^{11}$.

Regarding 'coloring of labels', the performance of the Experimental group exposed to colour coded labeling to coloured parts of an illustration showed no significant difference to the Control group who are exposed to no colour coded labeling of the same illustration. Moreover, there were a slight higher mean score found in the Control group. It may be assumed here that excessive use of colour coding might be hindering concentration. This aspect needs to be addressed more thoroughly. Moreover, it has the risk of either having the labels illegibly pale, or having the colours on the illustration too dark to distinguish between parts. No significant difference was found in the performance between the Experimental and Control groups when an illustration labeled from one side was shown to the Experimental group and that labeled form both sides was shown to the Control group, a higher mean score was found in the Experimental group though.

It is assumed that colour is a very important element of an illustration, and its design. Use of different colours may attract either more or less to an area or form of an illustration. It can also distract our eyes from an important part of an illustration. A study showed that colors can increase the level of attention and memory power ${ }^{12}$.

It is observed that the colour-coded schematics and realistic images were helpful in understanding anatomical concepts because they clarified the instructional message of the images, helped with orientation and ensured easier distinction between different structures. Also colour-coded schematics were used to reduce the complexity of realistic images and to provide directing codes to focus learners' attention ${ }^{13}$.

In addition, the colour is such an attribute, the like / dislike which is very likely to be determined by personal taste. However, it is understandable that the most important characteristic of a colour should be what makes / keeps the foreground material legible $^{14}$.

The learning performance of the nursing students revealed statistically significant finding on the use of 'magnifying from the original structure', where the Experimental group was shown an inset along with the normal view of the structure, and Control group was shown only an enlarged view of the part. This finding was consistent with existing notion that the use of 'inset' is a frequently used method in newspapers, comic strips and even in the electronic media ${ }^{14,15}$. Similar to effective technique used in mapping location, using inset provides depth-and-wide view simultaneously. Such technique will enhance the students' shortterm learning memory since the learners can better comprehend the detailed information, while still remaining intact with the location.

Regarding 'illustrating the dynamic flow', even illustration provides two information cues- figurative and textual that makes memorisation easier, but the learning performance of the nursing students did not reflect this attribute to a statistically significant level. However, the mean score was higher in the Experimental group than in the Control group. It may be more useful to use a combination of both in teaching, but in a wellplanned way ${ }^{15}$.

\section{CONCLUSIONS}

When effectiveness of various ways of the presenting slides was tested on the basis of short-term learning performances of nursing students, no significant differences were found with 5 ways with two exceptions. However, the results of these performances showed some trends like higher mean scores. The findings also suggests that the two significant ways of presenting neuroanatomy illustration should be used in combination to enhance nursing student's short-term learning memory.

It is difficult to distinguish between liking a presentation or being attracted by a presentation and achieving successful learning. Furthermore, whether being attracted ultimately leads to better learning is hard to ascertain. Therefore, empirical evidence regarding these two aspects should be looked for separately, not taking one granted for the other.

One should keep in mind that it is very difficult to generalize the findings across learning topics and across learners' learning styles. Thus, all results from neuroanatomy slides may not be equally valid in the field of histology. Similarly, all individual aspects may not be equally valid for visual, auditory, or tactile learners who like to learn more by seeing, by hearing and by doing respectively.

Although the study has used the term 'PowerPoint slides' as its principal material, it may be clarified that the findings can 
be extrapolated in many ways to the same 'ways' of presentation created by any other presentation software.

\section{ACKNOWLEDGEMENTS}

The authors would like to thank Medical Education Centre for Research, Innovation and Training (MECRIT) under Khesar Gyalpo University of Medical Sciences of Bhutan for providing support in conducting this research. The authors also would like to thank program leader and students, Faculty of Nursing and Public Health for allowing us and participating in this research.

\section{REFERENCES}

1. Carmichael SW, Pawlina W. Animated PowerPoint as a tool to teach anatomy, The Anatomical Record, 2000;261(02):838. [Full Text $\mid$ DOI]

2. Frey BA, Birnbaum DJ. Learners' perceptions on the value of PowerPoint in lectures, Educational Resources Information Center (ERIC), 2013; 24(2): 46-8. [Full Text]

3. Brenton H, Hernandez J, Bello F, Strutton P, Purkayastha $\mathrm{S}$, Firth T, et al. Using multimedia and web3D to enhance anatomy teaching, Computers \& Education. 2007;49(01): 32-53, viewed 26 May 2013. [Full Text | DOI]

4. Bartsch RA, Cobern KM. Effectiveness of PowerPoint presentations in lectures, Computers \& Education, 2003;41(01):77-86. [Full Text | DOI]

5. Xingeng D, Jianxiang L. Advantages and disadvantages of PowerPoint in lectures to science students, I.J. Education and Management Engineering, 2012; 9:61-5. [Full Text | DOI]

6. Atkinson RC, Shiffrin RM. Human memory: A proposed system and its control processes. The psychology of learning and motivation. New York: Academic Press. 1968;2(4):89195. [Full Text | DOI]
7. Dorji G, Wetasin K, Chhezom K, Uddin ME, Wangmo S. Preferences of Bangladeshi Anatomists on the use of Different Styles of Presenting Embryology Illustrations in PowerPoint Slides. Ann. Int. Med. Den. Res. 2020; 6(4):1721. [Full Text $\mid$ DOI]

8. Craig RJ, Amernic JH. PowerPoint presentation technology and the dynamics of teaching, Innovative Higher Education, 2006;31(03):147-160. [Full Text | DOI]

9. LaPorte RE, Linkov F, Villasenor T, Sauer F, Gamboa C, Lovalekar M, et al. Papyrus to PowerPoint (P 2 P): Metamorphosis of scientific communication, BMJ, 2002; 325(7378):1478-1481. [Full Text | DOI]

10. Tufte E. PowerPoint is evil: power corrupts. PowerPoint corrupts absolutely, Wired Megazine, 2003;11(9):1-3. [Full Text]

11. Doumont J. The cognitive style of PowerPoint: slides are not all evil, Technical Communication, 2005;52(01):64-70. [Full Text]

12. Dzulkifli MA, Mustafar MF. The influence of colour on memory performance: a review. Malays J Med Sci. 2013 March;20(2):3-9. [PubMed | Full Text | DOI]

13. Khalil MK, Lamar CH, Johnson TE. Using computer-based interactive imagery strategies for designing instructional anatomy programs, Clinical Anatomy, 2004;18(01):68-76. [Full Text | DOI]

14. Barric A, Davis D, Winker D. Image versus text in PowerPoint lectures: Who does it benefit? Journal of Baccalaureate Social Science Work. 2018; 23(1):91-109.

15. Rodney MS, Rickard E. Death to weak PowerPoint: strategies to create effective visual presentations. Front Psychol. 2014; 5:1138. [Full Text | DOI]

\section{AUTHORS CONTRIBUTION}

Following authors have made substantial contributions to the manuscript as under:

GD: Concept, design, data collection and analysis, manuscript writing and review.

KW: Concept, Design, data collection and analysis, manuscript writing and review

KC: Design, data collection and analysis, manuscript writing and review

NS: Design, analysis, manuscript writing and review

MD: Design, data collection and analysis, manuscript writing and review

Author agree to be accountable for all respects of the work in ensuring that questions related to the accuracy and integrity of any part of the work are appropriately investigated and resolved.

\section{CONFLICT OF INTEREST}

None

GRANT SUPPORT AND FINANCIAL DISCLOSURE

Bhutan Foundation 